\title{
A Study on HIV/TB Co-infection in and around Khammam, Telangana, India
}

\author{
Nella Harshini* and B. Anuradha \\ Mamata Medical College, Rotary Nagar, Khammam, Telangana 507002, India \\ *Corresponding author
}

\begin{tabular}{|l|}
\hline Ke y w o r d s \\
HIV, TB, Co- \\
infection, CD4 count, \\
CBNAAT.
\end{tabular}

\section{Introduction}

Tuberculosis is the most common opportunistic infection and the major cause of death in HIV positive patients all over the world accounting for $40 \%$ of all infections seen in individuals with HIV infection (Pape, 2004) It accounts for about $13 \%$ of deaths among HIV positive patients worldwide (Sharma et al., 2004, 2005; Arora et al., 1999; Gothi et al., 2004; Corbett et al., 2003).

In HIV/TB co-infected individual, TB and HIV potentiate one another, resulting in the accelerated deterioration of immunological functions and premature death of the individual if untreated (Getahun et al., 2010).
People living with HIV (PLHIV) are more prone to tuberculosis infection as the virus weakens the immune system (Dar es Salaam, Tanzania, 2006) in many ways such as disease progression to active TB, increasing the risk of reactivation of latent TB. Chances of TB infection also increase once exposed to tubercle bacilli in PLHA (Sharma et al., 2005; Badri et al., 2001).

Early and prompt diagnosis of infection and management of tuberculosis leads to the reduction of tuberculosis burden. However, in HIV infected individuals, diagnosis may be difficult as there is scanty sputum production, 
lack of caseous necrosis resulting in less no. of bacilli in sputum, and high incidence of non-tubercular mycobacterial infection (Dewan et al., 2015). As a result, there is an increase in smear negative tuberculosis and unremarkable chest radiographs leading to difficulties in reducing the tuberculosis burden (Lucas et al., 1994; Jones et al., 1993). Hence the sensitivity and specificity of sputum microscopy are decreased in HIV infected individuals (Dewan et al., 2015). To overcome these difficulties, sputum culture and sensitivity can be used but it takes 4-8 weeks to get results and not suitable for screening. This results in the delayed initiation of treatment, increasing the risk of transmission of tuberculosis in community and also increases the spread to extra pulmonary sites in the patient (Swaminathan et al., 2000).

CBNAAT, a polymerase chain reaction (PCR) based method which targets rpoB gene of mycobacterium, has been introduced recently for detection of $\mathrm{TB}$ and also rifampicin resistance. It is a specific, automated, cartridge-based nucleic acid amplification assay uses real-time PCR and provides results within 100 minutes. It targets rpoB gene, a gene associated with rifampicin resistance, by using 3 specific primers and 5 unique molecular probes. Hence it is highly specific test for detection of TB and rifampicin resistance (Swaminathan et al., 2000).

Studies showed an estimate about $9 \%$ of all TB cases in adults were prone to HIV infection worldwide and $12 \%$ of the total deaths from TB in the year 2000 was directly associated with HIV/TB co-infection (Corbett et al.,2003). The situation has become very serious due to increased incidence of TB by $>6 \%$ per year (Corbett et al., 2003).

In HIV prevalent countries, about $14-54 \%$ of HIV infected people were undiagnosed with
TB prior to death whose autopsy studies have shown disseminated TB (Haileyeus Getahun et al., 2007). In high burden TB countries, studies showed that several demographic and clinical factors are significantly associated with HIV/TB co-infection (do Prado et al., 2014; Kibert et al., 2013; Liu et al., 2015).

An estimate showed that 3.1 million deaths occur annually due to HIV/TB co-infection in South-east Asia (Joint United Nations Programme on HIV/AIDS and WHO 2002. AIDS Epidemic updates 2004. UNAIDS/04.45E. Geneva: UNAIDS; 2004).

In India, the incidence of $\mathrm{TB}$ in general population is estimated to be around 40\%; however, studies shown around 25-30\% of increased incidence of TB due to HIV infection (Raviglione et al., 1995, 2003).

As there is increased burden worldwide and all over India, this study is taken up to know the burden in and around Khammam. To know the socio-demographic profile along with CD4 count, Rifampicin resistance and ART status in patients with HIV/TB coinfection in our area.

\section{Materials and Methods}

A cross-sectional study was conducted among $107 \mathrm{HIV} / \mathrm{TB}$ co-infected patients attending ICTC \& ART centers in the Government District General Hospital, Khammam from July-November 2016 after obtaining institutional ethical committee clearance. HIV/TB co-infected patients of both genders and all age groups and followed up in ART clinic at district hospital, Khammam were included in the study.

The socio-demographic and clinical variables were collected by reviewing participants' documents using a checklist. HIV positive with TB negative individuals, HIV negative individuals, and HIV negative with TB 
positive individuals were excluded in the study.

\section{Operational definitions used}

As per the national guidelines, all HIV seropositive individuals were screened for TB routinely.

The diagnostic method used in these patients is CBNAAT which detects the tubercle bacilli along with resistance to rifampicin.

\section{Results and Discussion}

Our study comprised a total no. of 107 HIV seropositive and TB positive patients. Out of 107 individuals, $72(67.2 \%)$ were males and $35(32.7 \%)$ were females (Table 1$)$. In one study by Dewan et al., showed that $76 \%$ were males, 24\% were females (Dewan et al., JIACM 2015).

In other studies, it is observed that HIV/TB co-infection in males was $75.3 \%$ (Kamath et al., 2013) and 82\% (Patel et al., 2011) respectively which are correlating with our study.

Our study included the individuals of age group 10-60yrs with mean age of 35years. Majority of HIV-TB coinfection is seen in 3140years with $37(34.5 \%)$ followed by $34(31.7 \%)$ in the age group of 21-30years (Table 1). Similar observations are seen in a study which showed $76 \%$ belongs to age group of 21-40 years (Patel et al., 2011) which shows that this is the age of high sexuality and reproductive age.

In other study by Sandhya et al., observed that the most common age group affected was 21-40years $(47.5 \%)$ than other age groups (Sawant et al., 2011).

The present study showed that HIV/TB coinfection was high in married individuals $(87.8 \%)$ which indicates that heterosexual transmission is common (Table 1). In one study, Bernard J Ngwoki et al., (2008) observed that HIV/TB co-infection is more in married individuals (50\%). Other study by Ramanchandran Kamat et al., showed $56.1 \%$ of HIV/TB coinfection in married individuals (Kamath et al., Lung India 2013).

Our study showed that HIV/TB co-infection was more among individuals who are illiterates $(51.4 \%)$ followed by inidividuals with primary education (30\%) and it is less in individuals with above secondary education (3.7\%) (Table 1).

This high prevalence among illiterates and primarily educated individuals may be due to lack of awareness regarding modes of transmission of HIV and preventive measures. In studies, (Mohanty et al., 1993 and Rajsekaran et al., 2000) observed that $36.8 \%$ were manual laborers and $57.6 \%$ were farmers respectively.

Bhattacharya et al., 2011 reported $22.8 \%$ were illiterates and $60.9 \%$ were educated up to primary school.

Our study reported that Majority of HIV/TB co-infected individuals $(42.1 \%)$ were having CD4 count $<200$ cells $/ \mathrm{mm}^{3}$ and $30 \%$ of individuals were having CD4 count of 200349 cells $/ \mathrm{mm}^{3}$ (Table 2 ).

Tuberculosis occurs at any stage of CD4 cell count but majority of co-infection occurs with depletion of cell count. In HIV infected individuals, there is severe immunosuppression due to low CD4 cell count and the person is susceptible to TB infection or reactivation of latent infection leading to rapid progression of disease. 
Table.1 Socio-demographic profile among HIV/TB co-infected individuals

\begin{tabular}{|c|c|c|}
\hline $\begin{array}{l}\text { Socio-demographic } \\
\text { characteristics }\end{array}$ & Number of patients & Percentage $(\%)$ \\
\hline \multicolumn{3}{|l|}{ SEX } \\
\hline Male & 72 & 67.2 \\
\hline Female & 35 & 32.7 \\
\hline P value & $<0.05$ & \\
\hline AGE IN YEARS & NUMBER & PERCENTAGE (\%) \\
\hline $10-20$ & 4 & 3.7 \\
\hline $21-30$ & 34 & 31.7 \\
\hline $31-40$ & 37 & 34.5 \\
\hline $41-50$ & 21 & 19.6 \\
\hline $51-60$ & 8 & 7.5 \\
\hline$>60$ & 3 & 2.8 \\
\hline MARITAL STATUS & NUMBER & PERCENTAGE (\%) \\
\hline Married & 94 & 87.8 \\
\hline Unmarried/single & 9 & 8.4 \\
\hline Widow/divorced & 4 & 3.7 \\
\hline EDUCATION LEVELS & NUMBER & PERCENTAGE (\%) \\
\hline Illiterate & 55 & 51.4 \\
\hline Primary school & 32 & 30.0 \\
\hline Secondary school & 16 & 14.9 \\
\hline Inter \& above & 4 & 3.7 \\
\hline
\end{tabular}

Table.2 Distribution of CD4 count among HIV/TB co-infected individuals

\begin{tabular}{|c|c|c|}
\hline CD4 COUNT (CELLS/MM ${ }^{3)}$ & NUMBER & PERCENTAGE \\
\hline$<200$ & 45 & 42.1 \\
\hline $200-349$ & 32 & 30.0 \\
\hline $350-500$ & 6 & 5.6 \\
\hline$>500$ & 24 & 22.4 \\
\hline
\end{tabular}

Table.3 Rifampicin susceptibility among HIV/TB co-infected indviduals

\begin{tabular}{|l|c|c|}
\hline RIF SENSITIVITY & NUMBER & PERCENTAGE \\
\hline Rif resistance & 10 & 9.3 \\
\hline Rif sensitivity & 97 & 90.6 \\
\hline P VALUE & $<\mathbf{0 . 0 5}$ & \\
\hline
\end{tabular}


Table.4 ART status among HIV/TB co-infected individuals

\begin{tabular}{|l|c|c|}
\hline PRE-ART/ART & NUMBER & PERCENTAGE \\
\hline Pre-ART & 54 & 50.4 \\
\hline ART & 46 & 42.9 \\
\hline Others* & 7 & 6.5 \\
\hline P VALUE & $<\mathbf{0 . 0 5}$ & \\
\hline
\end{tabular}

*not taking treatment, transferred to native districts and does not come for follow-up.

TB in turn increases 6-7times of viral load in HIV seropositive individuals (Nissapatorn et al., 2003) our data correlates with other studies which showed $65 \%$ of HIV/TB coinfected patients had CD4 cell count $<349$ cells $/ \mathrm{mm}^{3}$ (Bernard J Ngwoki et al., 2008). Some other studies observed that HIV/TB coinfections are more common in individuals with CD4 count $<200$ cells $/ \mathrm{mm}^{3}$ than compared to HIV infection alone which shows that TB coinfection will enhance the morbidity and progression of HIV infection(Iredia et al., 2011 and Vajpayee M et al., AIDS Patient Care STDS 2004). In one study (Seada Mohammed et al., Int $J$ of Pharma Sciences and Research 2015), observed that $82 \%$ of HIV positive patients had CD4 cell count 200-500cells $/ \mathrm{mm}^{3}$ and most of the TB infection occurred in individuals $(57.8 \%)$ with CD4 cell count $<200$ cells $/ \mathrm{mm}^{3}$. This clearly shows that TB coinfection increases in HIV positive individuals with decrease in CD4 cell count. Similar observations were done by some studies where CD4 cell counts were $<200$ cells $/ \mathrm{mm}^{3}$ and severe immunosuppression in HIV/TB co-infected individuals when compared to HIV infection alone (Kamath et al., 2013; Belay et al., 2013; Taha M Deribew et al., 2011; Giri et al., 2013; Maruza et al., 2011). It is also important to detect MDR-TB in India where $\mathrm{TB}$ is endemic with a prevalence of $3 \%$ in new cases and 12-18\% in old tested cases (Chauhan, 2008) the sensitivity of sputum microscopy will be less in HIV/TB coinfection but can be detected better by
CBNAAT. Sensitivity and specificity of CBNAAT were reported to be $95 \%$. In our study, we have identified Rifampicin susceptibility to detect MDR-TB by CBNAAT. Out of $107 \mathrm{HIV} / \mathrm{TB}$ co-infected patients, only $10(9.3 \%)$ were resistant to Rifampicin and remaining 97(90.6\%) were sensitive to Rifampicin (Table 3). In one study, it is observed that out of 40 patients who were tested by CBNAAT 10 (25\%) were resistant to Rifampicin and 9/10 were MDRTB (R Dewan et al., 2015). In one study in northern Tanzania, it is observed that there is resistance to at least one drug among $10.8 \%$ of HIV/TB co-infections (Kibiki et al., 2007) which is correlating with our study. Studies (Sudha Mishra et al., 2015) reported that there is $14.71 \%$ of patients were resistant to rifampicin tested by conventional methods. Thus early screening of MDR-TB is important in HIV/TB co-infected patients.

In our study, out of $107 \mathrm{HIV} / \mathrm{TB}$ co-infected individuals, $54(50.9 \%)$ were on PreAntiretroviral Therapy (Pre-ART) and 46(42.9\%) were on Antiretroviral Therapy (ART) and the treatment status was not known in few individuals (Table 4). Among 10 individuals who were resistant to rifampicin, $8(80 \%)$ were on Pre-ART and $2(20 \%)$ were on ART which shows that with ART there is a decrease in MDR-TB. A study from Combodia shows that there is decrease in the resistance to anti-tubercular drugs from $48 \%$ in 1999 to $7.9 \%$ in 2004 with the introduction of antiretroviral therapy (Sungkanuparph et al., 2007). 
$\mathrm{TB}$ is the most common opportunistic infection in HIV infected individuals with CD 4 cell count $<350$ cells $/ \mathrm{mm}^{3}$ however it can occur at any stage of CD4 cell count. HIV/TB coinfections are more common in the age group of 21-40years affecting mainly males. Due to heterosexual transmission, married individuals are highly infected. Coinfections are commonly seen in illiterates due to lack of awareness regarding modes of transmission and prevention. In endemic areas like India, it is important to screen MDR-TB cases especially in the immunosuppressed individuals to identify early resistance and also to prevent the spread of MDR-TB.

\section{Acknowledgement}

The authors wish to thank all the HIVpositive persons who participated in this study, and also Dr. Ramesh, District Tuberculosis Officer, Khammam.

\section{References}

Arora VK, Kumar SV: Pattern of opportunistic pulmonary infections in HIV seropositive subjects: observations from Pondicherry, India. Indian J Chest Dis Allied Sci 1999,41:135044.

Badri M, Ehrlich R, Wood R, Pulerwitz T, Maartens G: Association between tuberculosis and HIV disease progression in a high tuberculosis prevalence area. Int J Tuberc Lung Dis 2001,5:225-32.

Belay A, Alamrew Z, Berie Y, Tegegne B, Tiruneh G, Feleke A. Magnitude and correlates of tuberculosis among HIV patients at Felege Hiwot Referral Hospital, Bahir Dar city, northwest Ethiopia. Clinical medicine research 2013;2:77-83.

Bernard J Ngwoki, Sayoki G Mfinanga, Johan $\mathrm{N}$ Bruun et al., Pulmonary tuberculosis among people living with HIV/AIDS attending care and treatment in rural northern Tanzania. BMC Public Health 2008,8:341.

Bhattacharya MK, Naik TN, Ghosh M, Jana S, Dutta P. Pulmonary tuberculosis among HIV seropositives attending a counseling center in Kolkata. Indian $J$ Public Health 2011;55:329-31.

Chauhan LS. Drug resistant TB-RNTCP response. Indian J Tuberc 2008;55(1):58.

Corbett EL, Watt CJ, Walker N, Mhae D, Williams BG, Raviglione MC et al., the growing burden of tuberculosis: Global trends and interactions with HIV epidemic. Arch Intern Med 2003;163:1009-21.

do Prado TN, Miranda AE, de Souza FM, Dias ES, Sousa LKF, Arakaki-Sanchez D. Factors associated with tuberculosis by HIV status in the Brazilian national surveillance system: a cross sectional study. BMC Infect Dis 2014;14:415.

Getahun H, Gunneberg C, Granich R, Nunn $\mathrm{P}(2010) \quad$ HIV infection-associated tuberculosis: the epidemiology and the response. Clin Infect Dis 50 suppl 3: S201-S207.

Giri PA, Deshpande JD, Phalke DB. Prevalence of pulmonary tuberculosis among HIV positive patients attending antiretroviral therapy clinic. $N A m J$ Med Sci 2013;5:367-70.

Gothi D, Joshi JM: Clinicak and laboratory observations of tuberculosis at a Mumbai (India) clinic. Postgrad Med J 2004, 80:97-100.

Haileyeus Getahun MH, O’Brien R, Nunn P: Diagnosis of smear-negative pulmonary tuberculosis in a people with HIV infection or AIDS in resourcecoinstrained settings: informing urgent policy changes. Lancet public health 2007, 368(9578):2042-2049.

Iredia $\mathrm{CH}$, Oguntibeju OO, Lewis HA, Mokwena K. Trends and characteristics 
of patients admitted with musculoskeletal tuberculosis to a referral hospital from 2003 to 2008. Afr J Microbiol Res 2011;5:532-40.

Joint United Nations Programme on HIV/AIDS and WHO 2002. AIDS Epidemic updates 2004. UNAIDS/04.45E. Geneva: UNAIDS; 2004

Jones BE, Young SM, Antoniskis D, Davidson PT, Kramer F, Barnes PF: Relationship of the manifestations of tuberculosis to CD4 cell counts in patients with HIV infection. Am Rev Respir Dis 1993, 148:1292-7.

Kamath R, Sharma V, PattanshettyS, Hegde MB, Chandrasekaran V. HIV-TB coinfection: Clinico-epidemiological determinants at an antiretroviral therapy center in Southern India. Lung India 2013;30:302-6.

Kibert KT, Yalew AW, Belaineh BG, Asres MM. Determinant factors associated with occurrence of tuberculosis among adult people living with HIV after Antiretroviral treatment initiation in Addis Ababa, Ethiopia: A case control study. PLoS ONE 2013;8:e64488.

Kibiki GS, Mulder B, Dolmas WM, de Beer JL, Boeree M, Sam N, van Soolingen D, Sola C, Zanden AG van der: $M$. tuberculosis genotypic diversity and drug susceptibility pattern in HIVinfected and non-HIV-infected patients in northern Tanzania. BMC Microbial 2007, 7:51.

Liu E, Makubi A, Drain P, Spiegelman D, Sando D, Lin N et al., Tuberculosis incidence rate and risk factors among HIV-infected adults with access to antiretroviral therapy. AIDS 2015;29:1391-9.

Lucas SB, De Cock KM, Hounnou A, Peacock C, Diamonde M, Honde M, Beaumel A, Kestens L, Kadio A: Contribution of tuberculosis to slim disease in Africa. BMJ 1994, 308:15313.

Maruza M, Albuquerque MF, Coimbra I, Moura LV, Montarroyos UR, Miranda Filho DB et al., risk factors for default from tuberculosis treatment in HIVinfected individuals in the state of Pernambuco, Brazil: a prospective cohort study. BMC Infect Dis 2011;11:351.

Ministry of Health and Social Welfare Tanzania: Manual of the National Tuberculosis and Leprosy Programme in Tanzania. Dar es Salaam, Tanzania 2006.

Mohanty KC, Sundrani RM, Nair S. HIV infection in patients with respiratory disease. Indian J Tuberc 1993;40:5.

Nissapatorn V, Christopher L, Init I, Mun Yik F, Abdullah KA. Tuberculosis in AIDS patients. Malays Med Sci 2003;10:60-4.

Pape JW: Tuberculosis and HIV in the Caribbean: approaches to diagnosis, treatment, and prophylaxis. Top HIV Med 2004,12:144-9.

Patel AK, Thakrar SJ, Ghanchi FD. Clinical and laboratory profile of patients with TB/HIV coinfection: A case series of 50 patients. Lung India 2011;28:93-6.

R Dewan, S Anuradha, AKhanna, S Garg, S Singla, P Ish, S Agarwal, A Narayana H, M Hanif, H Singh, S Uppal: Role of cartridge-based nucleic acid amplification test(CBNAAT) for early diagnosis of pulmonary tuberculosis in HIV. JIACM 2015,16(2): 114-7.

Rajasekaran R, Lima A, Kamakshi S, Jeyaganesh D, Senthamizhchelvan A, Savithrr S et al., Trend of HIV infection in patients with tuberculosis in rural south India. Indian $J$ Tuberc 2000;47:223.

Raviglione MC, Snider DE, Kochi A. Global epidemiology of tuberculosis morbidity and mortality of a worldwide epidemic. JAMA 1995;273:220-6. 
Saeda Mohammed, Tewelde Tesfaye Gebremariam. Tuberculosis among HIV- positive patients at Butajira hospital, south-central Ethiopia. Int $J$ of Pharma Sciences and Research 2015:1406-11

Sawant SS, Agrawal SR, Shastri JS, Pawaskar M, Kadam P. Human immunodeficiency virus infection among tuberculosis patients in Mumbai. J Lab Physicians 2011;3:12-4.

Sharma SK, Kadhiravan T, Banga A, Goyal T, Bhatia I, Saha PK: Spectrum of clinical disease in a series of 135 hospitalized HIV-infected patients from north India. BMC Infect Dis 2004,4:52.

Sharma SK, Mohan A, Kadhiravan T: HIVTB coinfection: epidemiology, diagnosis and management. Indian $J$ Med Res 2005, 121:550-67.

Sudha Mishra, Atul Rukadikar. Prevalence of pulmonary Tuberculosis in HIV positive individuals, its sensitivity and Association with CD4 Count. Int.
J.Curr. Microbiol. App.Sci 2015;4(6):292-304.

Sungkanuparph S, Eampokalap B, Chottanapud S, Bed ST, Manosuthi W: Declining prevalence of drug-resistant tuberculosis among HIV/tuberculosis co-infected patients receiving antiretroviral therapy. J Med Assoc Thai 2007, 90:884-8.

Swaminathan S, Ramachandran R, Baskaran $\mathrm{G}$ et al., risk of development of tuberculosis in HIV-infected patients. Int J Tuberc Lung Dis 2000;4(9): 83944.

Taha M Deribew A, Tessema F, Assegid S, Duchateau L, Colebunders R. risk factors of active tuberculosis in people living with HIV/AIDS in southwest Ethiopia: a case control study. Ethiop $J$ health Sci 2011;21:131-139.

Vajpayee M, Kanswal S, Seth P, Wig N, Pandey RM. Tuberculosis infections in HIV-infected Indian Patients. AIDS Patient Care STDS 2004; 18:209-13.

\section{How to cite this article:}

Nella Harshini and Anuradha, B. 2017. A Study on HIV/TB Co-infection in and around Khammam, Telangana. Int.J.Curr.Microbiol.App.Sci. 6(11): 3698-3705. doi: https://doi.org/10.20546/ijcmas.2017.611.433 